OPEN ACCESS

Edited by:

John L. Provis,

University of Sheffield, UK

Reviewed by:

Ionut Ovidiu Toma,

Gheorghe Asachi Technical

University of lași, Romania

Kenan Song,

Massachusetts Institute of

Technology, USA

*Correspondence:

Han-Yong Jeon

hyjeon@inha.ac.kr

Specialty section:

This article was submitted to

Structural Materials,

a section of the journal

Frontiers in Materials

Received: 31 May 2016

Accepted: 22 September 2016

Published: 12 October 2016

Citation:

Jeon H-Y (2016) Analysis of Environmental Applicability of HDPE

Geomembrane by Simulated

Applicability Testing for Waste

Containment Construction.

Front. Mater. 3:44.

doi: 10.3389/fmats.2016.00044

\section{Analysis of Environmental Applicability of HDPE Geomembrane by Simulated Applicability Testing for Waste Containment Construction}

\author{
Han-Yong Jeon* \\ Department of Applied Organic Materials Engineering, Inha University, Incheon, South Korea
}

Geosynthetic separation boxes made from recycled polymeric materials were designed to increase the waste landfill amount and develop the hydraulic performance in steep slope sides in the waste landfills. To evaluate the advantages of these geosynthetic separation boxes, index tests were conducted in order to compare the geonet composites and geosynthetic separation boxes. The tensile strength retention of the geosynthetic separation box plates exposed to UV light and leachate solutions was better than that of the geonet composites. The drainage performance of the geosynthetic separation boxes was compared with that of the geonet composites at a slope angle corresponding to a real waste landfill site. The drainage performance of the geosynthetic separation box plates was better than that of the geonet composites.

Keywords: geosynthetic separation boxes, waste storage and drainage efficiencies, geonet composites, tensile strength retentions, drainage performance, slope angle

\section{INTRODUCTION}

Many waste landfills in Korea are constructed between valleys and have very steeply sloping sides $\left(\right.$ more than $30^{\circ}$ ). Therefore, large quantities of sand or backfill soils are required to increase the stability of the side slopes and, as a result, the total volume available for waste disposal is decreased by the amount shown by the oblique lines in Figure 1 (Gourc and Villard 2000; McBean et al., 1995). The resulting reduction in the waste storage volume is one of the main reasons why the construction of waste landfills is often considered to be uneconomic (Koerner, 2005). The use of geosynthetic separation box in the waste landfill sites, which are made from recycled waste polymeric materials, reduces the total cost of constructing waste landfills, because they are cheaper to produce. The inner sides of these geosynthetic boxes are open, and they can be filled with sand, soil, rubble, or other materials, in order to fix them to the slopes of the waste landfills. The use of such filler materials in the geosynthetic boxes allows good drainage performance, as well as increased stability of the side slopes of the waste landfills, because of their reinforcement effects.

In this study, geosynthetic separation boxes, which have the same performance as geomembrane in waste landfill sites that were composed of regenerated high density polyethylene (HDPE), were used to increase the waste landfill amount and develop the hydraulic performance in steep slope sides in the waste landfills. The tensile strength retention of the geosynthetic separation box plates when exposed to UV and leachate solutions were examined and their properties assessed by comparing them to the theoretical values appropriate for waste landfills. The drainage performance of the 
A

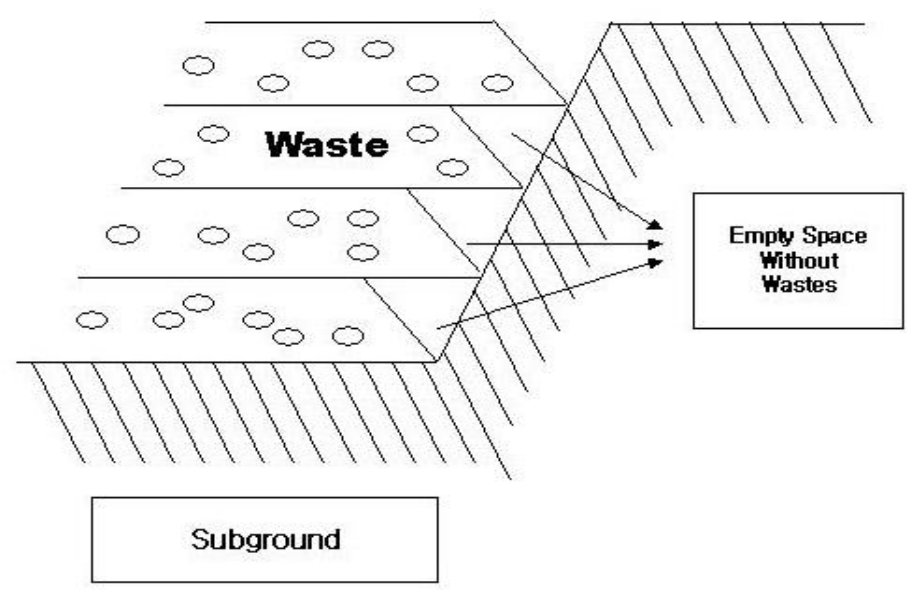

without geosynthetic separation boxes

B

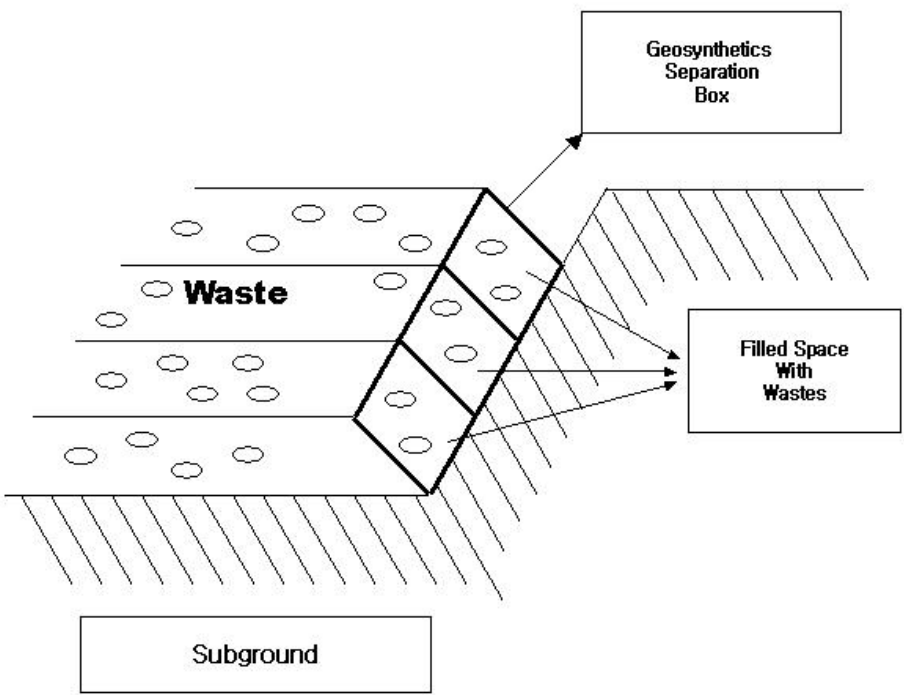

with geosynthetic separation boxes

FIGURE 1 | Schematic diagram of waste landfills with and without geosynthetic separation boxes. (A) Without geosynthetic separation boxes. (B) With geosynthetic separation boxes.

geosynthetic separation boxes was examined and compared with that of the geonet composites.

\section{EXPERIMENTAL}

\section{Manufacture of Geosynthetic Separation Boxes}

A plate size of geosynthetic separation box, $\operatorname{HDPE}(2)$, of recycled HDPE is $1 \mathrm{~m} \times 1 \mathrm{~m}$, and two plates of geosynthetic separation boxes were connected to each other continuously, as represented in Figure 2. Sand, gravel, and rubble were used as the filler materials between the upper and bottom plates of the boxes. Geonet composite, a non-woven/geonet/non-woven structure that is generally applied to the slopes of waste landfills in Korea, was used as a basis of comparison with the $\operatorname{HDPE}(2)$ plates of the geosynthetic separation boxes.

\section{Performance Assessment of Geosynthetic Separation Boxes}

To evaluate the advantages of the geosynthetic separation boxes, index tests of the plates were conducted to compare the two cases in which the geonet composites and geosynthetic separation boxes were used in the side slopes of the waste landfills, as shown in Figure 3, where GCL means geosynthetic clay liner. The tensile properties and chemical and UV resistance of the recycled HDPE plates were examined in accordance with ASTM D6693/ 


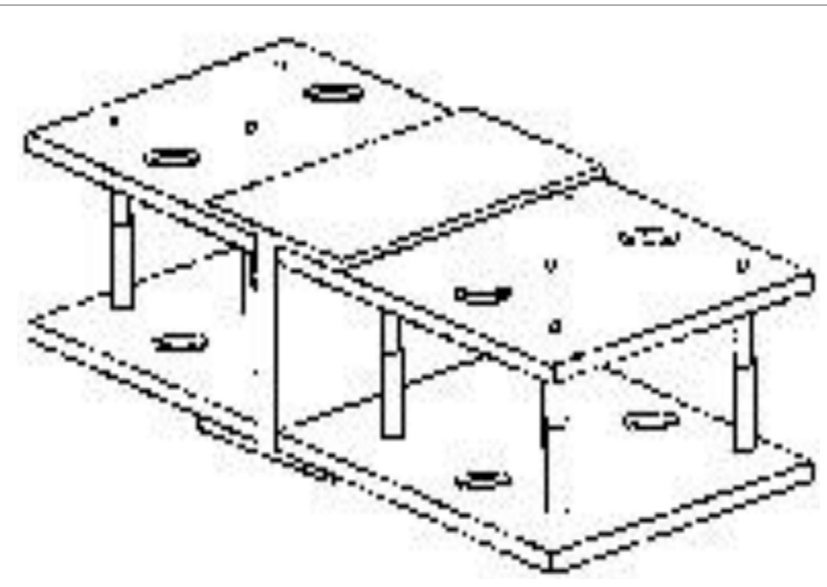

FIGURE 2 | Photograph of geosynthetic separation box.
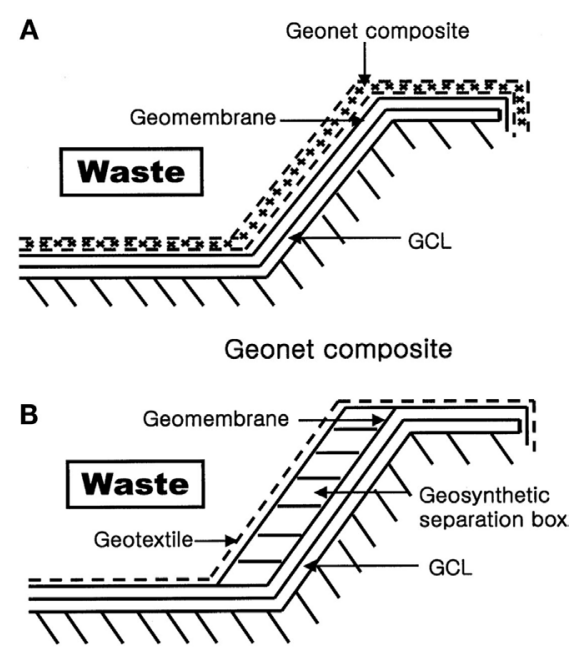

Geosynthetic separation box

FIGURE 3 | Schematic diagram showing the application of the (A) geonet composite and (B) geosynthetic separation boxes to the sloping sides of a waste landfill.

D6693M-04(2015)e1 (2015), ASTM D4355/D4355M-14 (2014), and ASTM D5322-98(2009) (2009), respectively. The hydraulic flows were measured by evaluating the amounts of water loss in accordance with ASTM D4716/D4716M-14 (2013) and ASTM D5493-06(2011) (2011) between geonet/non-woven geotextile composite and a plate of geosynthetic separation boxes.

\section{RESULTS AND DISCUSSION}

\section{Properties of Geosynthetic Separation Boxes \\ Tensile Strength Retentions}

Table 1 shows the tensile properties of the recycled and normal $\operatorname{HDPE}(1)$ plates used in the separation boxes. It is seen that
$\operatorname{HDPE}(2)$ plate has a higher tensile strength than $\mathrm{HDPE}(1)$ plate, but tensile elongation of $\operatorname{HDPE}(2)$ plate is lower than $\operatorname{HDPE}(1)$ plate. This result is due to the low stress resistance of $\operatorname{HDPE}(2)$ plate. Degrees of chemical resistances of these two HDPE plates were determined to evaluate the tensile strength retention ratio after 120 days of experimental duration under immersing in leachate solution with $\mathrm{pH} 3$ and 12 , and temperatures 25 and $50^{\circ} \mathrm{C}$, respectively. Degrees of UV resistances were also estimated from the tensile strength retention ratio using the xenon arc method. Table 2 shows the tensile strength retention ratios of the recycled HDPE(2) plates and geonet/non-woven geotextile composite. As shown in Table 2, chemical and UV resistances of the recycled $\operatorname{HDPE}(2)$ plates by comparing tensile strength ratio before/after experimental duration were better than those of the geonet/ non-woven geotextile composite when recycled geosynthetic separation box of $\operatorname{HDPE}(2)$ used to waste landfill site.

\section{Properties of Separation Boxes When Applied to Waste Landfills}

The properties of the geosynthetic separation boxes made of $\operatorname{HDPE}(2)$ when applied to the slopes of waste landfills were estimated by comparing them with the theoretical requirements for the tensile strength and coefficient of permeability in waste landfill conditions.

\section{Tensile Strength of Separation Boxes}

For an external load $W$ and a waste landfill with slope angle $\beta$, the breaking force of the separation box plate consists of the driving force and the resistance against the driving force, which are defined as $W \sin \beta$ and $F$, respectively, as shown in Figure 4. Here, the factor of safety (FS) means the ratio of $W \sin \beta$ to $F$ in Eq. 1.

$$
\mathrm{FS}=\frac{\text { resisting } \times \text { force }}{\text { driving } \times \text { force }}=\frac{F}{W \sin \beta}
$$

TABLE 1 | Tensile properties of HDPE plates in the machine direction.

\begin{tabular}{lcc}
\hline HDPE plates & \multicolumn{2}{c}{ Tensile properties } \\
\cline { 2 - 3 } & Strength $\mathbf{( k g / \mathbf { c m } ^ { 2 } )}$ & Elongation $\mathbf{( \% )}$ \\
\hline $\operatorname{HDPE}(1)$ & 32.4 & 603.5 \\
$\operatorname{HDPE}(2)$ & 36.7 & 107.4 \\
\hline
\end{tabular}

(1) HDPE plate with a thickness of $3 \mathrm{~mm}$ used for geomembranes.

(2) Recycled HDPE plate with a thickness of $3 \mathrm{~mm}$ used for geosynthetic separation box.

TABLE 2 | Tensile strength retentions of separation box plate and geonet composite.

Geosynthetics Tensile strength retention (\%)

\begin{tabular}{|c|c|c|c|c|}
\hline & \multicolumn{2}{|c|}{$\mathrm{pH} 3$} & \multicolumn{2}{|c|}{ pH 12} \\
\hline & $25^{\circ} \mathrm{C}$ & $50^{\circ} \mathrm{C}$ & $25^{\circ} \mathrm{C}$ & $50^{\circ} \mathrm{C}$ \\
\hline \multicolumn{5}{|c|}{ (a) Chemical resistance } \\
\hline HDPE(2) & 92.6 & 88.2 & 91.2 & 86.4 \\
\hline Geonet composite & 92.4 & 88.6 & 92.6 & 88.2 \\
\hline \multicolumn{5}{|l|}{ (b) UV resistance } \\
\hline HDPE(2) & 92.4 & & & \\
\hline Geonet composite & 90.6 & & & \\
\hline
\end{tabular}




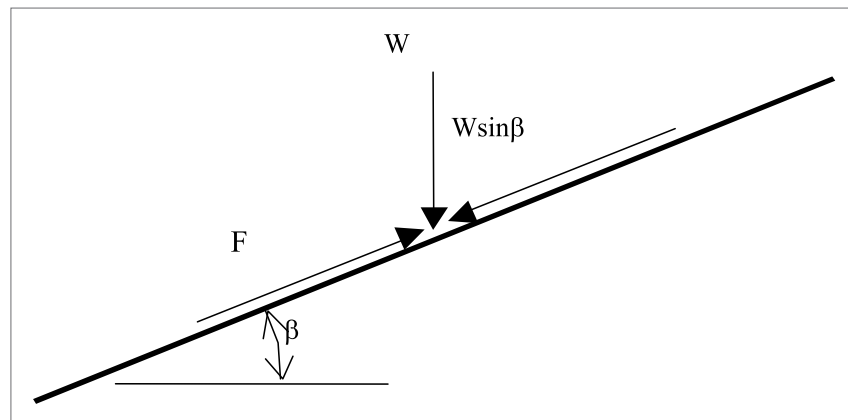

FIGURE 4 | Schematic diagram of acting loads in waste landfills

If we consider the following installation conditions, the driving and resistance forces are described by Eq. 1.

- slope angle $(\beta): 15^{\circ}, 30^{\circ}, 45^{\circ}$, and $50^{\circ}$;

- height of waste landfill: 3, 5, 10, 20, 50, and $100 \mathrm{~m}$;

- density of waste: $1.4 \mathrm{ton} / \mathrm{m}^{3}$;

- weight of final covering: vegetation layer + drainage layer $=$ $1 \mathrm{~m} \times 1.7\left(\mathrm{ton} / \mathrm{m}^{3}\right)$, compaction layer $=0.6 \mathrm{~m} \times 2\left(\mathrm{ton} / \mathrm{m}^{3}\right)$;

- safety factor: 1.5 ;

- driving forces: $1400 \mathrm{~kg} / \mathrm{m}^{3} \times$ height of waste landfill + (weights of vegetation and drainage layers) $\times \sin \beta$;

- resistance forces $=1.5 \times$ driving forces.

Table 3 lists the required tensile strengths of the HDPE(2) plates of the geosynthetic separation boxes for waste landfills with the given slope angles and heights. For example, the minimum tensile strength of the $\operatorname{HDPE}(2)$ plates of a geosynthetic separation box must be $1.05 \mathrm{~kg} / \mathrm{cm}^{2}$, if the slope angle is $45^{\circ}$ and the height of the waste landfill is $5 \mathrm{~m}$.

\section{Drainage Performances}

The hydraulic performance of two HDPE(1) and (2) were determined by comparing the water flow amount for the case of with and without using the filling materials, such as sand, soil, and fly ash, which increase the cohesive force between wastes and filling materials. Permittivity as a tool of hydraulic performance of $\operatorname{HDPE}(2)$ plate with holes was better than that of the geonet/ non-woven geotextile composite.

\section{Numbers of Holes in Separation Box Plates}

For the geosynthetic separation box to have excellent permeability, it is necessary to maintain the optimum hole size in the plates. The minimum area of the holes was calculated with regard to the standard permittivity of waste landfills in Korea, which is required to be greater than $1 \times 10^{-2} \mathrm{~cm} / \mathrm{s}$. In this study, the minimum areas of the holes per unit area $(1 \mathrm{~m} \times 1 \mathrm{~m})$ of the $\operatorname{HDPE}(2)$ plate were calculated by considering the following permittivity ranges:

- for sand: $1 \times 10^{0}-1 \times 10^{-3} \mathrm{~cm} / \mathrm{s}$;

- for gravel: $1 \times 10^{2}-1 \times 10^{-1} \mathrm{~cm} / \mathrm{s}$; and

- for filler materials: $1 \times 10^{-1} \mathrm{~cm} / \mathrm{s}$.

In Figure 5, the thickness, hole diameter, and distance between the separation boxes are designated as A, B, and C,
TABLE 3 | Tensile strength $\left(\mathrm{kg} / \mathrm{cm}^{2}\right)$ of separation box plate as a function of the slope angle ( $\beta)$ and height of the waste landfill.

\begin{tabular}{lllllllr}
\hline & \multicolumn{7}{c}{ Height of waste landfill } \\
\cline { 3 - 8 } & & $\mathbf{3} \mathbf{~ m}$ & $\mathbf{5 ~ \mathbf { ~ }}$ & $\mathbf{1 0} \mathbf{~ \mathbf { ~ }}$ & $\mathbf{2 0} \mathbf{~ \mathbf { ~ }}$ & $\mathbf{5 0} \mathbf{~ \mathbf { ~ }}$ & $\mathbf{1 0 0} \mathbf{~}$ \\
\hline Slope angle $(\beta)$ & $15^{\circ}$ & 0.28 & 0.38 & 0.66 & 1.20 & 2.83 & 5.55 \\
& $30^{\circ}$ & 0.53 & 0.74 & 1.27 & 2.32 & 5.47 & 10.72 \\
& $45^{\circ}$ & 0.75 & 1.05 & 1.79 & 3.28 & 7.73 & 15.16 \\
& $50^{\circ}$ & 0.82 & 1.14 & 1.94 & 3.55 & 8.38 & 16.42
\end{tabular}

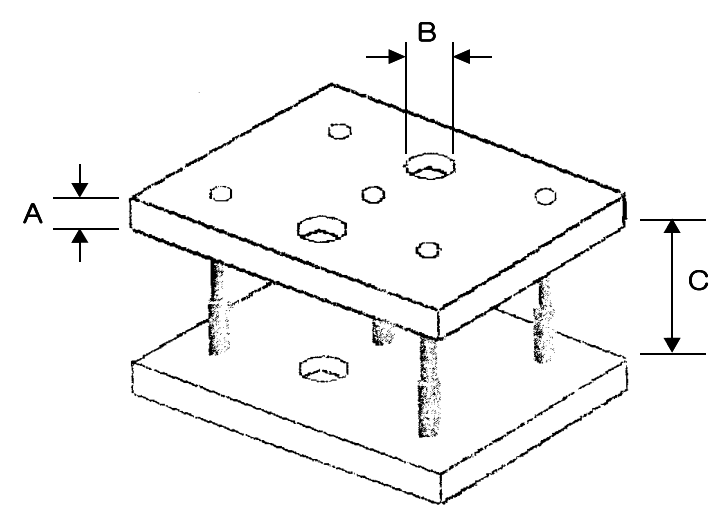

FIGURE 5 | Configuration of separation box with drainage holes (A) thickness; $5 \mathrm{~mm}$, (B) diameter; $10 \mathrm{~mm}$, (C) height; $30 \mathrm{~mm}$.

respectively. From Darcy's law, the flux of this model can be written as follows.

$$
\begin{gathered}
v=k \cdot i \\
Q=v \cdot A \\
Q=k \cdot i \cdot A
\end{gathered}
$$

where $v$ is discharge velocity (centimeter per second), $k$ is permittivity (centimeter per second), $i$ is hydraulic gradient, $Q$ is flux (cubic centimeter per second), and $A$ is unit area (square centimeter).

For hydraulic gradients of two or five with the above conditions, $v$ is constant even if $k$ decreases, and this is because of the increase in $i$. The minimum numbers and areas of holes are shown in Table 4, as a function of the hole diameter and hydraulic gradient per unit plate in the separation box. The required hole number of a plate in geosynthetics separation box are shown in Table 5, as a function of the permittivity and fraction of holes. For FS value, 2.0 was based on considering the clogging phenomena of a plate by filling materials. From Table 5, it is known that reasonable fraction range of holes per plate in geosynthetics separation box could $10-20 \%$ for using sand as a filling material which has permittivity $(\mathrm{cm} / \mathrm{s})$ is $5.0-1.0 \times 10^{-1}$.

\section{Required Strength of Separation Box under Load by Filling Materials}

Figure 6 shows a schematic diagram of a waste landfill slope with a geosynthetic separation box. Figure 7 shows the slope angles of 
TABLE 4 | Minimum number and area of holes in the unit plate in the separation box as a function of the diameter of the holes and hydraulic gradient.

\begin{tabular}{lcc}
\hline Hydraulic gradient & $\mathbf{2}$ & $\mathbf{5}$ \\
\hline Area $\left(\mathrm{cm}^{2}\right)$ & 10,000 & 10,000 \\
Drainage layer $k(\mathrm{~cm} / \mathrm{s})$ & $1.0 \mathrm{E}-01$ & $1.0 \mathrm{E}-01$ \\
Acceptable $k(\mathrm{~cm} / \mathrm{s})^{\mathrm{a}}$ & $1.0 \mathrm{E}-02$ & $1.0 \mathrm{E}-02$ \\
Hole diameter $(\mathrm{cm})$ & 1.0 & 2.0 \\
Discharge $\left(\mathrm{cm}^{3} / \mathrm{s}\right)^{\mathrm{b}}$ & 2000.0 & 5000.0 \\
First $v(\mathrm{~cm} / \mathrm{s})$ & 0.2 & 0.5 \\
Acceptable discharge $\left(\mathrm{cm}^{3} / \mathrm{s}\right)^{\mathrm{c}}$ & 200 & 500 \\
Minimum area $\left(\mathrm{cm}^{2}\right)^{\mathrm{d}}$ & 1000 & 1000 \\
Fraction of holes $(\%)$ & 10 & 10 \\
Minimum numbers of holes & 1273 & 1273
\end{tabular}

astandard permittivity.

${ }^{b}$ Flux of drainage layer.

'Flux through separation box.

${ }^{d}$ Cross-sectional area of drainage layer with flux through separation box.

TABLE 5 | Minimum numbers of holes per unit plate in the separation box as a function of the permittivity and fraction of holes.

\begin{tabular}{lrrrr}
\hline Permittivity (cm/s) & $\mathbf{0 . 0 5}$ & $\mathbf{0 . 1 1}$ & $\mathbf{0 . 5}$ & $\mathbf{1}$ \\
\hline Fraction of holes (\%) & 20 & 10 & 2 & 1 \\
Hole diameter, $1 \mathrm{~cm}$ & 2547 & 1273 & 255 & 127 \\
Hole diameter, $1.5 \mathrm{~cm}$ & 1132 & 566 & 113 & 57 \\
Hole diameter, $2 \mathrm{~cm}$ & 637 & 318 & 64 & 32 \\
Hole diameter, $3 \mathrm{~cm}$ & 283 & 141 & 28 & 14 \\
Hole diameter, $5 \mathrm{~cm}$ & 102 & 51 & 10 & 5
\end{tabular}

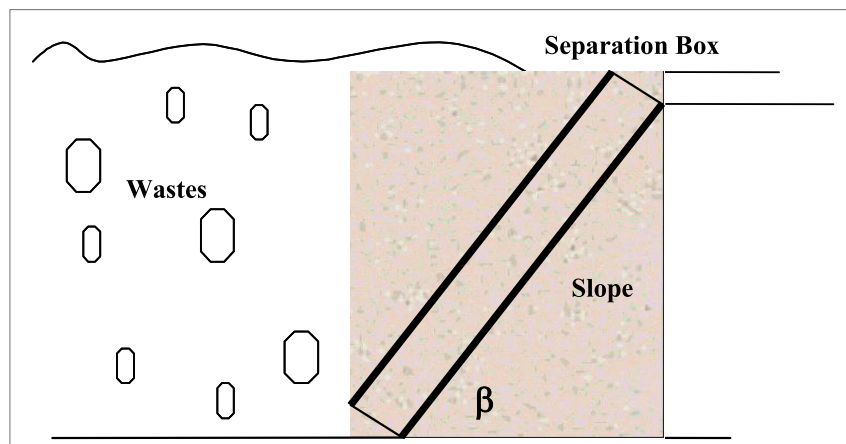

Landfill Ground

FIGURE 6 | Schematic diagram of waste landfill slope with geosynthetic separation box.

the $\operatorname{HDPE}(2)$ plates of the separation boxes, where the slope angle of the separation box is $\beta$. The following assumptions were used to calculate the loads resulting from the filler materials:

- filler material: sand;

- density of sand: $1.6 \mathrm{ton} / \mathrm{m}^{3}$ (dry weight);

- general range of dry-weight density of sand:1.47-1.63 ton $/ \mathrm{m}^{3}$;

- no water in the drainage layer before landfill;

- slope angle of separation box $(\beta): 30^{\circ}$.

The minimum required strengths of the unit plates of a separation box were determined for the following lengths of slope and slope angles.

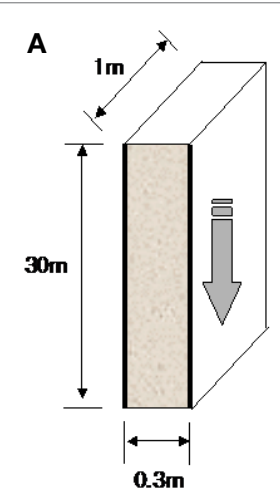

B

FIGURE 7 | Slope angle, $\beta$, for HDPE(2) plate of geosynthetic separation box: (A) $90^{\circ}$ and (B) $45^{\circ}$.

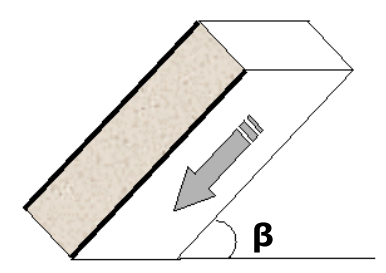

TABLE 6 | Minimum required strength $\left(\mathrm{kg} / \mathrm{cm}^{2}\right)$ as a function of length and angle of the slope for sand and gravel.

\begin{tabular}{|c|c|c|c|}
\hline \multirow[t]{2}{*}{ Slope angle ( $\beta$ ) } & \multicolumn{3}{|c|}{ Slope length } \\
\hline & $10 \mathrm{~m}$ & $30 \mathrm{~m}$ & $50 \mathrm{~m}$ \\
\hline \multicolumn{4}{|c|}{ (a) For sand (1.6 ton $\left./ \mathrm{m}^{3}\right)$} \\
\hline $15^{\circ}$ & 0.41 & 1.24 & 2.07 \\
\hline $30^{\circ}$ & 0.80 & 2.40 & 4.00 \\
\hline $45^{\circ}$ & 1.13 & 3.39 & 5.66 \\
\hline $50^{\circ}$ & 1.23 & 3.68 & 6.13 \\
\hline \multicolumn{4}{|c|}{ (b) For gravel (2.0 ton $\left./ \mathrm{m}^{3}\right)$} \\
\hline $15^{\circ}$ & 0.52 & 1.55 & 2.59 \\
\hline $30^{\circ}$ & 1.00 & 3.00 & 5.00 \\
\hline $45^{\circ}$ & 1.41 & 4.24 & 7.07 \\
\hline $50^{\circ}$ & 1.53 & 4.60 & 7.66 \\
\hline
\end{tabular}

- length of slope: 10,30 , and $50 \mathrm{~m}$;

- slope angle: $15^{\circ}, 30^{\circ}, 45^{\circ}$, and $50^{\circ}$;

- unit weight of filler materials: sand $\left(1.6 \mathrm{ton} / \mathrm{m}^{3}\right)$ and gravel $\left(2.0\right.$ ton $\left./ \mathrm{m}^{3}\right)$.

Table 6 shows the minimum required strengths in the case of sand and gravel as a function of the length of the slope and slope angle. For example, in Table 6 (a), the minimum required strength of the unit plate of the separation box should be $6.13 \mathrm{~kg} / \mathrm{cm}^{2}$ for a slope length of $50 \mathrm{~m}$ and a slope angle of $50^{\circ}$. In Table 6 (b), the minimum required strength of the unit plate of the separation box should be $7.66 \mathrm{~kg} / \mathrm{cm}^{2}$ for a slope length of $50 \mathrm{~m}$ and a slope angle of $50^{\circ}$. From the above analysis, it can be seen that the geosynthetic separation box made of recycled HDPE plates has excellent performance when applied to waste landfill slopes.

\section{CONCLUSION}

HDPE(2) plate in the geosynthetic separation box has the reasonable tensile strength and elongation values to compare $\operatorname{HDPE}(1)$ plate to consider the case of waste landfill slope application. For degree of chemical and UV resistance, $\operatorname{HDPE}(2)$ plate showed the same result as tensile properties before mentioned. 
Permittivity as a hydraulic performance of $\operatorname{HDPE}(2)$ plate showed an excellent result than HDPE(1). From this result, it is seen that $\operatorname{HDPE}(2)$ plate for the geosynthetic separation boxes takes a better and reasonable material to stabilize and reinforce the slope side of waste landfills. Also, HDPE(2) plate for the geosynthetic separation boxes can be instead of geonet/non-woven geotextile composite in the steep slope side of waste landfills. However, further performance study of the HDPE(2) plate in the geosynthetic separation boxes must be conducted to confirm these results to satisfy the long-term performance during service period of waste landfills.

\section{AUTHOR CONTRIBUTIONS}

Most of the contents were written by Prof. H-YJ, and also he did test for evaluation of engineering performance of recycled HDPE geomembranes. Prof. H-YJ, male, geosynthetics/technical organic materials researcher, graduated from Textile Engineering department, Hanyang University in 1979. He worked for Hyejeon College, 1982-1990, Howon University, 1990-1992, Chonnam National University, 1992-2005, and now works for

\section{REFERENCES}

ASTM D4355/D4355M-14. (2014). Standard Test Method for Deterioration of Geotextiles by Exposure to Light, Moisture and Heat in a Xenon Arc Type Apparatus. West Conshohocken, PA: ASTM International. Available at: www. astm.org

ASTM D4716/D4716M-14. (2013). Standard Test Method for Determining the (In-Plane) Flow Rate per Unit Width and Hydraulic Transmissivity of a Geosynthetic Using a Constant Head. West Conshohocken, PA: ASTM International. Available at: www.astm.org

ASTM D5322-98(2009). (2009). Standard Practice for Immersion Procedures for Evaluating the Chemical Resistance of Geosynthetics to Liquids. West Conshohocken, PA: ASTM International. Available at: www.astm.org

ASTM D5493-06(2011).(2011). Standard Test Method for Permittivity of Geotextiles under Load. West Conshohocken, PA: ASTM International. Available at: www. astm.org

ASTM D6693/D6693M-04(2015)e1. (2015). Standard Test Method for Determining Tensile Properties of Nonreinforced Polyethylene and Nonreinforced Flexible Polypropylene Geomembranes. West Conshohocken, PA: ASTM International. Available at: www.astm.org
Inha University. Since 1998, he is the director of Geosynthetics Institute (USA)-Korea Directory. He worked in International Geosynthetics Society as Council member (2006-2012), and he was the sixth president of Korean Geosynthetics Society (2011-2013). Also, he is member of ASTM D35 and ISO TC221 on geosynthetics from 1998. Now, he is the current 32nd President of Korean Fiber Society (2014-2015). He has published more than 782 papers in domestic and international conferences. He wrote 17 texts including "GEOSYNTHETICS" and also published 114 papers in domestic and international journals. He received awards of Marquis Who's Who - Science and Engineering in 2003-2014 and Top 100 Scientists in the World: 2005/2011 of IBC (International Biographical Centre, UK). Also, he got the 33rd Academy Award of Korean Fiber Society in 2006 and "Excellent Paper Award of 2012" by The Korean Federation of Science and Technology Societies.

\section{ACKNOWLEDGMENTS}

This work was supported by INHA UNIVERSITY Research Grant.

Gourc, J. P., and Villard, P. (2000). "Reinforcement by membrane effect: application to embankments on soil liable to subsidence," in Proceedings of the 2 nd Asian Geosynthetics Conference, ASIA 2000, Kuala Lumpur, Malaysia, 29-31 May 2000, Vol. 1, p. 55-72.

Koerner, R. M. (2005). Designing with Geosynthetics, 5th Edn. Upper Saddle River: Prentice Hall.

McBean, E. A., Rovers, F. A., and Farquhar, G. J. (1995). Solid Waste Landfill Engineering and Design. Englewood Cliffs: Prentice Hall, 155-206.

Conflict of Interest Statement: The author declares that the research was conducted in the absence of any commercial or financial relationships that could be construed as a potential conflict of interest.

Copyright (C) 2016 Jeon. This is an open-access article distributed under the terms of the Creative Commons Attribution License (CC BY). The use, distribution or reproduction in other forums is permitted, provided the original author(s) or licensor are credited and that the original publication in this journal is cited, in accordance with accepted academic practice. No use, distribution or reproduction is permitted which does not comply with these terms. 